\title{
The pull-out test on knit bamboo reinforcement embedded into concrete beam
}

\author{
Devi Nuralinah ${ }^{1, *}$ \\ ${ }^{1}$ Department of Civil Engineering, Brawijaya University, 65145 MT Hartono 167 Malang, Indonesia
}

\begin{abstract}
The pull-out test is generally conducted to obtain accurately the carrying capacity of the flexural strength of the knit bamboo reinforced concrete beam, which is more determined by the bonding strength than the tensile strength of reinforcement in concrete. Bamboo bar with braid knit which was coated with sikadur as bonding agent based on selected epoxy resin was expected to improve a good friction with concrete. In the pull-out test method, a hydraulic jack was applied to encourage bamboo embedded into a pair of concrete blocks, whose size was $15 \mathrm{~cm}$ x $30 \mathrm{~cm}$ x $40 \mathrm{~cm}$. The experimental variable of specimens were types of knitted bamboo, and type of coating. Based on the test results, either the bond strength or the tensile strength, which was calculated based on the failure mechanism, increased with respect to the concrete quality. The compressive strength of concrete was averaged as much as $25,97 \mathrm{MPa}$. The usage of outer skin surface on the cutting braid knit bamboo (type 1), which was coated with sikadur experimentally could increase the pull-out load. In the pull-out test, bond failure occurred with using of the plain bamboo bar with the bond stress of $1.18 \mathrm{MPa}$, while tensile failure occurred with using of knit bar type 1 with peak tensile strength of $85.84 \mathrm{Mpa}$.
\end{abstract}

\section{Introduction}

Kinds of research were conducted to reduce the shrinkage of bamboo reinforcement in structural concrete that caused the bonding failure. The influence of coating of knit bamboo with varnish could increase the bonding stress in concrete [1,2].

Bond strength is caused by the shear interlock between the reinforcement and the concrete. It means a combination of the ability between the reinforcement and the concrete that covers it in forces resistance that can cause the bonding to lose between the rebars and the concrete [3].

The bond stress between bamboo and concrete can experimentally be determined by the pull-out test. In this research, variations of knit bamboo and coating were used to examine the failure mechanism and the bond strength.

\section{Literature review}

Bond stress is the shear stress on the surface of the concrete, where the load transfer occurs between the reinforcement steel and the surrounding concrete so as to modify the stress of the reinforcing steel. This bonding is effectively distributed, and allows two material forms a composite structure, as shown in Fig. 1 that illustrates the behavior of the bonding along the reinforcement.
The embedment length determines the resistance of bar slip. The main basis of the embedment length theory is to take into account an embedded reinforcement in concrete.
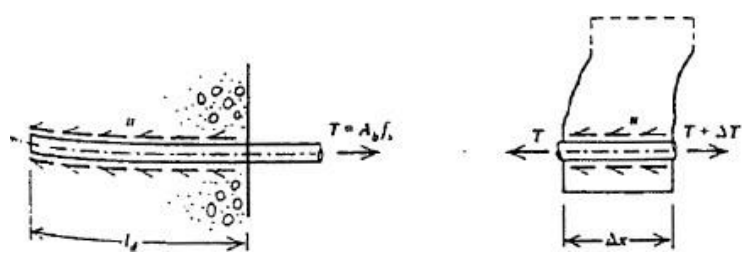

Fig. 1. Anchorage and flexural bonding of tensile bars.

In order to transfer the force completely through the bond, it is needed to embed the bars into the concrete to a certain depth, which is expressed in the embedment length. The tensile force acting on the reinforcement can be retained by the bonding between the surrounding concrete and the reinforcement. When this bond stress acts evenly over the entire embedded bars, the total force to be resisted before pulling out the rod from the concrete will be equal to the multiplication of length of the embedded bars, its circumference, and the bond stress. In the calculation of the amount of reinforcement that is embedded in the concrete required the bond stress $(\mu)$. This means that the tension is related to the embedded length of reinforcement on concrete. So that

\footnotetext{
* Corresponding author: devi@ub.ac.id
} 
the pull-out load of bars embedded in concrete can be formulated as follows [4]:

$$
P_{\max }=\mu\left(l_{d} * p\right)
$$

Where: $P_{\max }$ is the maximum pull-out load

$\mu$ is the bond stress

$l_{d}$ is embedment length

$p$ is the circumference of bars

The bonding mechanism between concrete and reinforcement can be conducted by a pull-out test on a reinforced embedded in concrete. In the pull-out test, the pull-out load and also the bond stress can be obtained. The influencing factors of bond strength between concrete and reinforcement are as following factors [5]:

(1) gripping effect (holding) as a result of drying shrinkage of concrete around the reinforcement and friction between reinforcement and the surrounding concrete; (2) friction resistance against the slip and interlock each other when the reinforcement experiences tensile stress; (3) diameter of reinforcement; (4) coating material, and (5) concrete cover.

The bonding of reinforcement to the concrete occurs due to several factors, including the chemical adhesion between two materials, the friction due to the natural roughness of the reinforcement, and the effect of the tightly deformed bars to the reinforcing surface of the concrete [6].

The relatively low bonding stress on the plain round rebars will cause a slip which adequately removes the adhesion at a location adjacent directly to the location in the concrete so that the relative friction between the reinforcement and the surrounding concrete is only held up by friction along the slip region.

Deformed bars are installed to adjust a behavior that depends on the surface area of friction and adhesion and depends more on the resistance of its knot to the concrete.

Bond stress between the concrete and the reinforcement can be reduced when the stress increases so that cracks will arise in the concrete, then development cracks will result in deflection.

\section{Experimental methods}

\subsection{Specimens}

In the pull-out test, three types of knit bamboo with the outer skin surface, shown in Fig. 2 were controlled by plain bamboo whose size was $0.7 \times 0.7 \times 124$. Each knit bamboo contained three slices of bamboo including outer skin surface. In order to reduce the shrinkage of bamboos, the coating material of either varnish or sikadur was used. Sikadur is a bonding agent based on selected epoxy resin. In addition, varnish is a transparent, hard, protective finish or film that is primarily used not only in wood finishing but also for other materials.

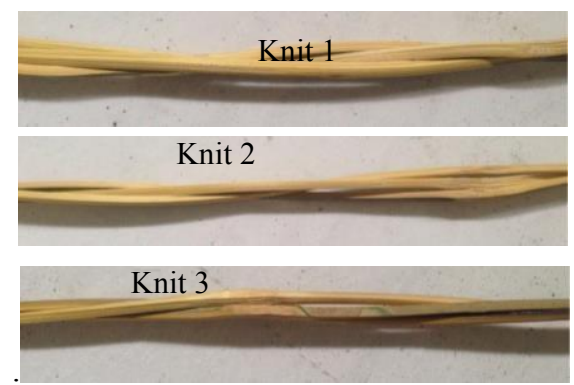

Fig. 2. Variation of knit bamboo bars.

Two bamboo reinforcements were embedded into a pair of concrete block specimens with the size of each 40x15x30cm, as shown in Fig. 4. Variables of the pullout specimens were tabulated in Table 1. Types of bamboo and coating were already described in subsection 3.1. In the preliminary test, both bonding agents were coated on the surface of bamboo knit with braid configuration (knit 1). The best result of them was considered for further variables with different bamboo types in the pull-out test.

For preservation, bamboo bars were immersed previously with $\mathrm{NaOH}$ and dried naturally before knitting and coating process. The accelerator type of admixture additive was added in all concrete mixture. To measure the characteristic compressive strength of 20 $\mathrm{MPa}$, concrete cylinders were cast. Pull-out and cylinder specimens were cured for 10 days (same with 28 days in normal concrete) and respectively tested with pull-out test and compressive test as explained in subsection 3.2.

Table 1. Variable of the pull-out specimen.

\begin{tabular}{|c|c|c|c|c|}
\hline \multirow{2}{*}{ Specimens } & \multicolumn{2}{|c|}{ Bamboo types } & \multicolumn{2}{|c|}{ Coat types } \\
\cline { 1 - 3 } $\mathrm{A}_{1} \mathrm{~B}_{1}$ & \multirow{2}{*}{ Knit 1} & $\mathrm{~A}_{1}$ & \begin{tabular}{c} 
Sikadur \\
\cline { 1 - 3 }
\end{tabular} & $\mathrm{B}_{1}$ \\
\hline $\mathrm{A}_{1} \mathrm{~B}_{2}$ & & $\mathrm{~h}$ & $\mathrm{~B}_{2}$ \\
\hline $\mathrm{A}_{2} \mathrm{~B}_{1}$ & Knit 2 & $\mathrm{~A}_{2}$ & Sikadur & $\mathrm{B}_{1}$ \\
\hline $\mathrm{A}_{3} \mathrm{~B}_{1}$ & Knit 3 & $\mathrm{A}_{3}$ & Sikadur & $\mathrm{B}_{1}$ \\
\hline $\mathrm{A}_{0} \mathrm{~B}_{1}$ & $\begin{array}{c}\text { No knit or } \\
\text { plain bamboo }\end{array}$ & $\mathrm{A}_{0}$ & Sikadur & $\mathrm{B}_{1}$ \\
\hline
\end{tabular}

Many tensile specimens with a flat shoulder made from bamboo were designed to be used with serrated grips. Each sample had two shoulders larger than a gauge section which expected to collapse. The dimension of the flat test specimen according to actual and ASTM B557M standard were shown in Table 2 and described in Fig 3. 
Table 2. The size of the flat test specimen.

\begin{tabular}{|c|c|c|c|}
\hline \multirow[b]{2}{*}{ Nominal length } & \multirow[b]{2}{*}{ Symbol } & \multicolumn{2}{|c|}{ Dimension (mm) } \\
\hline & & $\begin{array}{c}\text { Actual } \\
\text { (Measurement) }\end{array}$ & $\begin{array}{c}\text { Standard } \\
\text { (ASTM) }\end{array}$ \\
\hline Gauge length & $G$ & 50 & $50 \pm 0.10$ \\
\hline Width & $W$ & 18.3 & $12.5 \pm 0.05$ \\
\hline Thickness & $T$ & 13.41 & 5 \\
\hline $\begin{array}{l}\text { Overall length } \\
(\min )\end{array}$ & $L$ & 350 & 200 \\
\hline $\begin{array}{l}\text { Length of grip } \\
\text { section (min) }\end{array}$ & $B$ & 100 & 50 \\
\hline $\begin{array}{l}\text { Width of grip } \\
\text { section (approx) }\end{array}$ & C & 20 & 20 \\
\hline $\begin{array}{l}\text { Length of } \\
\text { reduced section }\end{array}$ & $A$ & 50 & 57 \\
\hline
\end{tabular}
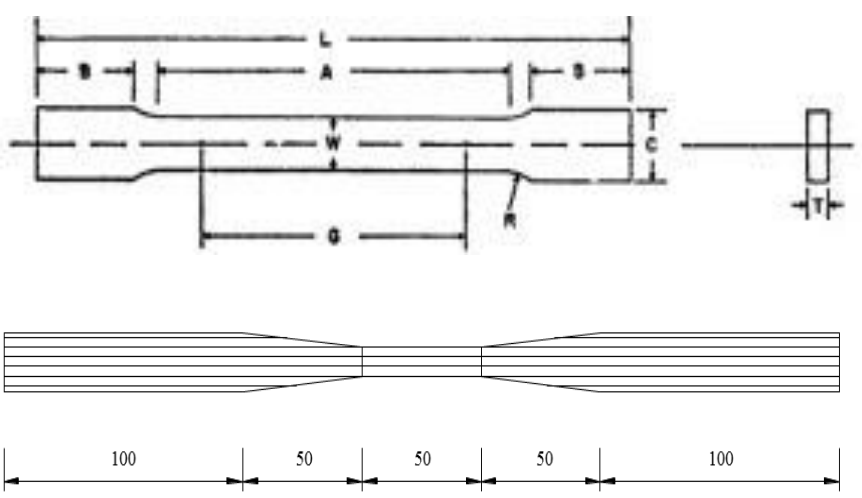

Fig. 3. The dimension of the flat tensile test specimen.

\subsection{Testing device}

Testing of materials was initially prepared instead of identifying their characteristics. Testing of aggregates such as density and absorption was conducted previously to describe the appropriate proportion of concrete mix.

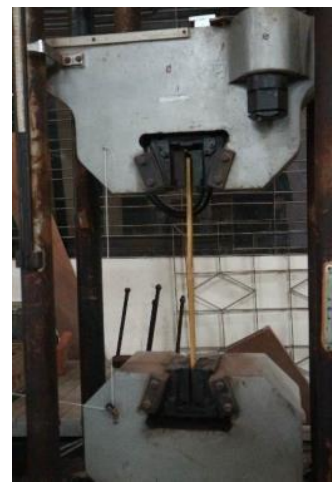

Fig. 4. Outline of the tensile test.
Load carrying capacity of bamboo bars is more commonly determined by pull-out test than the tensile test. In this research, almost all tensile strength of bamboo specimen could not be obtained by Universal Testing Machine due to the slip failure at the grip side, though the bamboo was formed to the flat tensile test specimen. The installation of the tensile test can be seen in Fig. 4.

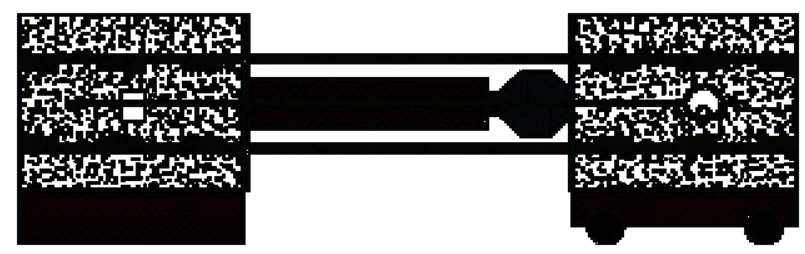

Fig. 5. Outline of the pull-out test.

In this recent pull-out test method, hydraulic jack, piston, and load cell were set up to test the specimen, as seen in Fig. 5. Bamboo was identified as a weak material compared with steel so that it was easy to be broken under tensile test by Universal Testing Machine device [7]. Therefore, the proposed method was usable in the pull-out test.

The compressive strength of cylinder concrete mixing for pull-out specimens was also measured here by Compressive Testing Machine as seen in Fig. 6.

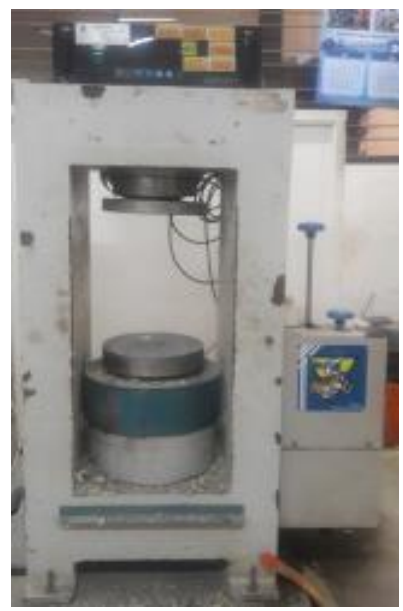

Fig. 6. Compressive strength machine.

Since the bond stress between bamboo and concrete was influenced by concrete quality, cylinder specimens of each pull-out concrete mixture were prepared and tested. The process of the pull-out test is briefly explained in Fig. 7. 


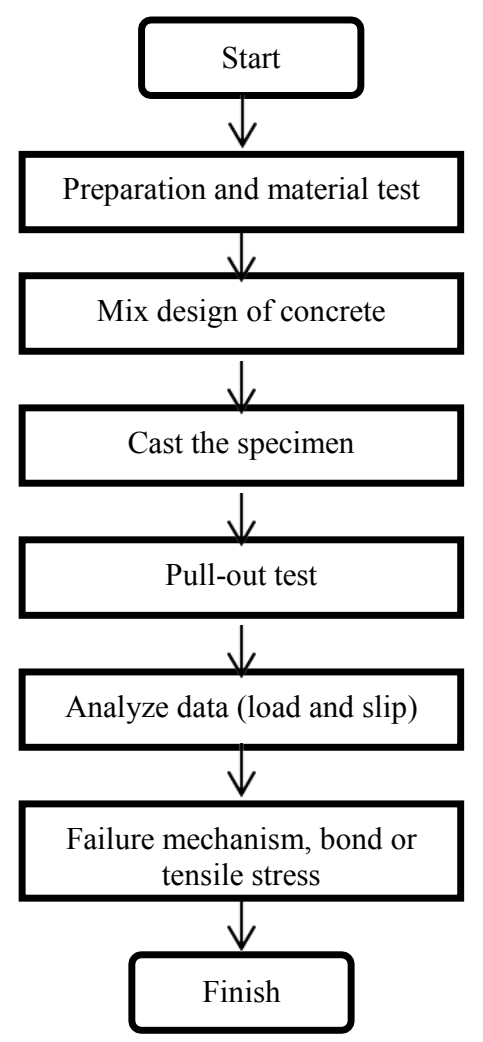

Fig. 7. Research step of pull-out test.

\section{Result and analysis}

\subsection{Tensile test}

Table 3. The results of the tensile test specimen.

\begin{tabular}{|c|c|c|c|}
\hline $\begin{array}{c}\text { Specime } \\
\mathrm{n}\end{array}$ & Failure & Specimen & Failure \\
\hline $\mathrm{N}-1$ & Tensile failure & $\mathrm{WN}-1$ & Slip failure \\
\hline $\mathrm{N}-2$ & Slip failure & $\mathrm{WN}-2$ & Slip failure \\
\hline $\mathrm{N}-3$ & Slip failure & WN-3 & Slip failure \\
\hline $\mathrm{N}-4$ & Slip failure & WN-4 & Slip failure \\
\hline $\mathrm{N}-5$ & Slip failure & WN-5 & Slip failure \\
\hline
\end{tabular}

Note: $\mathrm{N}=$ bamboo with nodia, $\mathrm{WN}=$ bamboo without nodia

The failure mechanism of the tensile test specimen shown in Table 3, and Fig. 8 did not satisfy because of slip failure in the grip side under testing by Universal Testing Machine, as explained before.

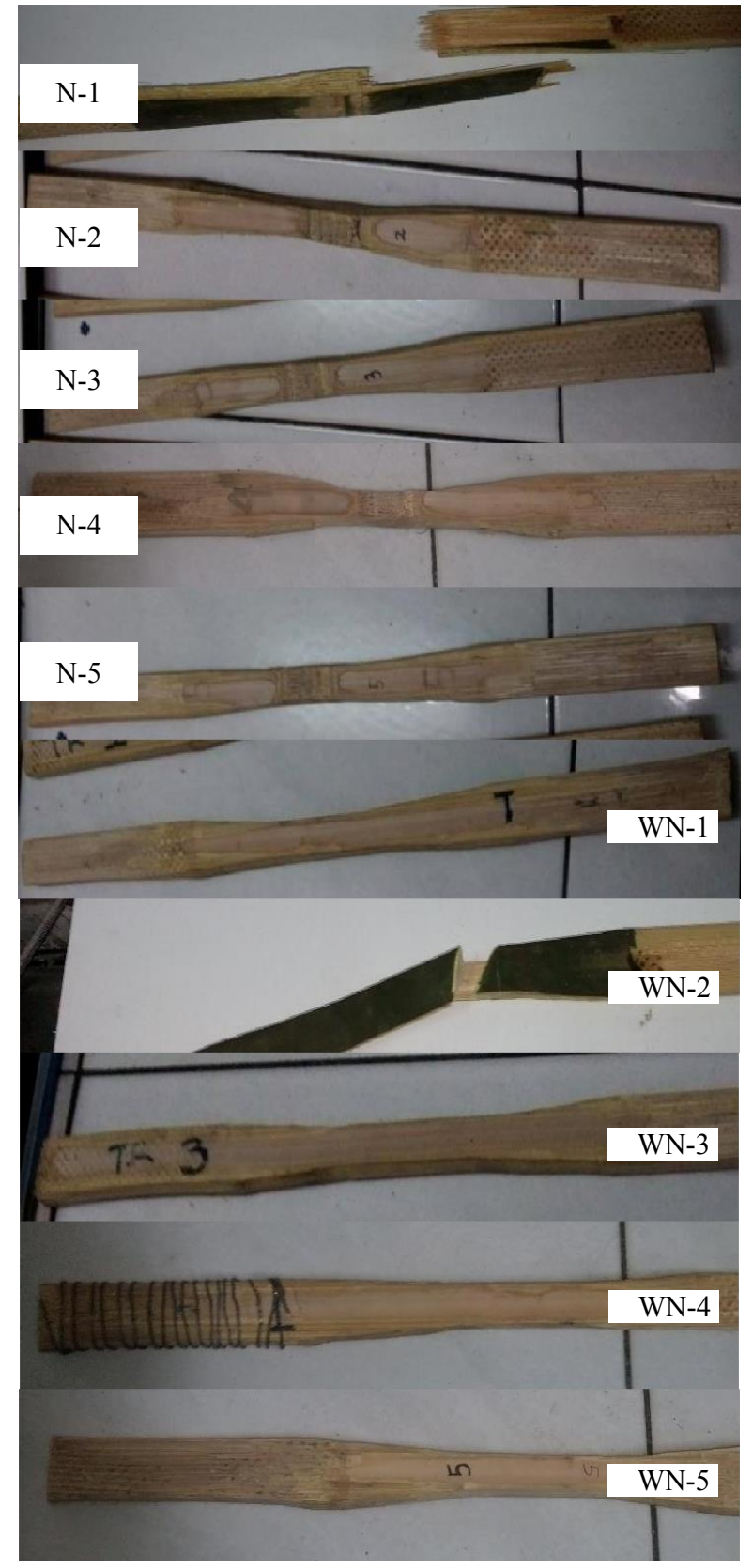

Fig. 8. Tensile failure of bamboo.

\subsection{Compressive test}

The averaged compressive strength of cylinder specimens could be seen in Table 4. The test result of specimen A0B1 was insignificant because the concrete mixture was not compacted well compared with other specimens. 
Table 4. The results of the compressive test specimen.

\begin{tabular}{|c|c|}
\hline Specimen & $\begin{array}{c}\text { Averaged compressive } \\
\text { strength (MPa) }\end{array}$ \\
\hline A1B1 & 31.4 \\
\hline A2B1 & 29.3 \\
\hline A3B1 & 26.0 \\
\hline A0B1 & 17.0 \\
\hline
\end{tabular}

\subsection{Pull-out test}

The pull-out test that results in the peak load can be used to calculate the bond stress between bamboo bars and concrete.

Fig. 9a shows a relationship between the pull-out load and slip in specimen reinforced with knit bamboo type 1 coated with sikadur. From the test result, that specimens have the greatest pull-out load about $23 \mathrm{kN}$ in average, and slip about $5 \mathrm{~mm}$ in average because bamboo knit 1 has high friction force with concrete. Usage of sikadur can increase the pull-out load, that is why it was chosen as the coating for other knit variations.

Pull-out load of specimens with knit bamboo type 2 and 3 are almost similar about $13 \mathrm{kN}$. Slip between bamboo and concrete in the specimen with bamboo type 3 is smaller than the specimen with bamboo type 2 (Fig 9b, 9c).

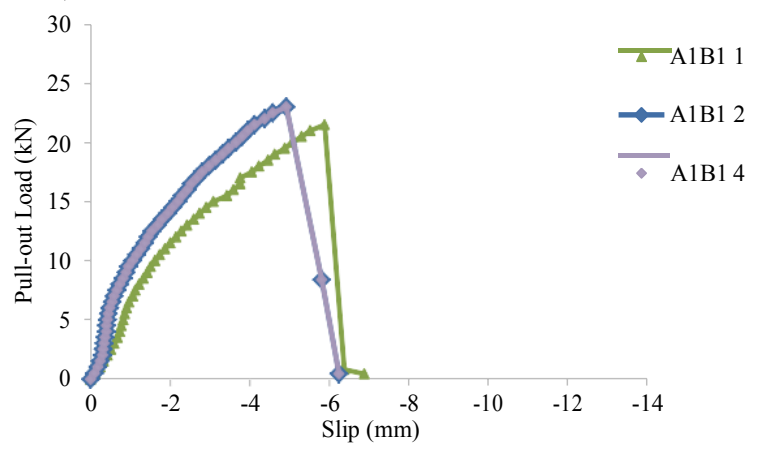

Fig. 9a. The pull-out load and slip curve of specimens with knit bamboo type 1 coated with sikadur

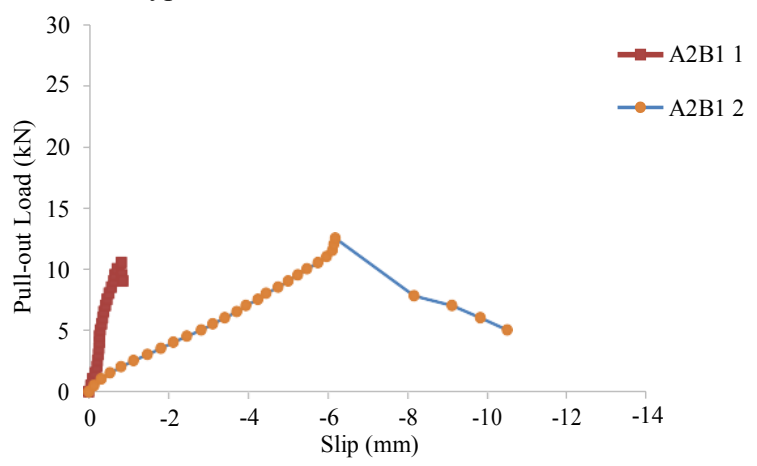

Fig. 9b. The pull-out load and slip curve of specimens with knit bamboo type 2 coated with sikadur

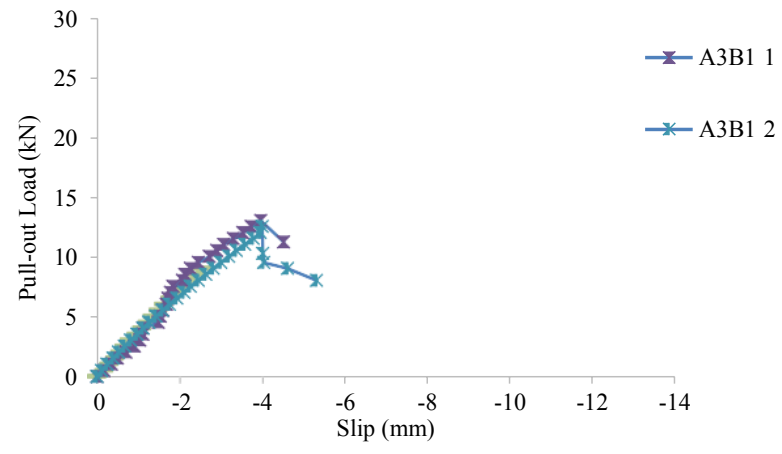

Fig. 9c. The pull-out load and slip curve of specimens with knit bamboo type 3 coated with sikadur

Fig. 9d shows that the ability of plain bamboo to carry pull-out load is slightly higher than knit bamboo. However, plain bamboo goes through slip greater than knit bamboo.

In Fig. 9e, the specimen with knit bamboo type 1 coated by varnish could carry the pull-out load slightly lower about $5 \mathrm{kN}$ than that coated with sikadur. However, the slip behavior, in this case, cannot be compared to each other due to an insignificant result of repetition sample (Fig. 9e).

The usage of either plain or knitted bamboo bars was to identify the failure mechanism in the pull-out test but could not clearly show the maximum load that can be carried each other. The maximum load of plain bamboo is $13.25 \mathrm{kN}$, higher than knit bamboo. It may be caused by the determination of cross-section area, and the twisting effect on the fiber hardness. Nevertheless, among knitted bamboo variation, braid type 1 (A1B1) carried the average maximum load about $11.13 \mathrm{kN}$.

The results show that the specimen reinforced with knit bamboo type 1 can improve more the pull-out load than the others. Specimen coated with sikadur can carry the pull-out load better than varnish and uncoated one.

It is found that knit bamboo can improve the bonding stress, but decrease the load carrying capacity in comparison with plain bamboo. The pull-out load in this research is also used to calculate the bond stress or tensile stress, which is dependent on the failure pattern.

\subsection{Failure mechanism}

The slip failure generally occurs in the pull-out test, when the bonding strength of bamboo bars is less than the yield strength.

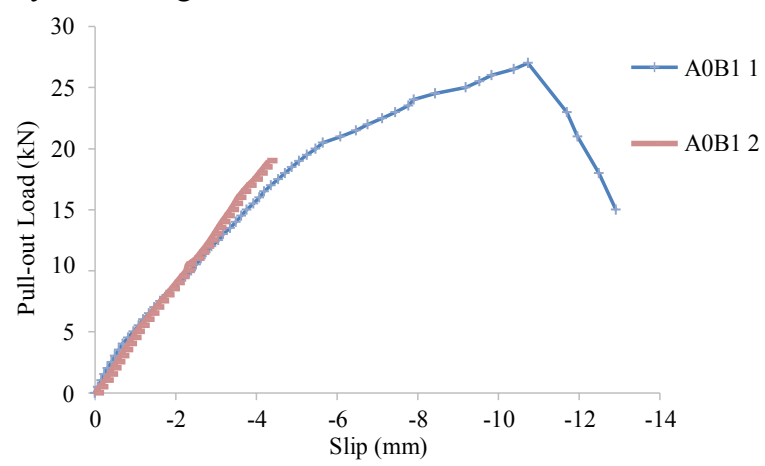

Fig. 9d. The pull-out load and slip curve of specimens with plain bamboo (no knit) coated with sikadur 


\begin{tabular}{|c|c|c|c|c|}
\hline Specimen & Failure types & $\begin{array}{c}\text { Pull-out } \\
\text { load } \\
(\mathrm{kN})\end{array}$ & $\begin{array}{c}\text { Bond } \\
\text { stress, } \\
\mu \mathrm{B} \\
(\mathrm{MPa})\end{array}$ & $\begin{array}{c}\text { Tensile } \\
\text { stress, } \\
\mu \mathrm{T} \\
(\mathrm{MPa})\end{array}$ \\
\hline A1B1 & Tensile failure & 11.13 & - & 85.84 \\
\hline A2B1 & Tensile failure & 5.75 & - & 44.37 \\
\hline A3B1 & Tensile failure & 6.38 & - & 49.19 \\
\hline A0B1 & Pull-out failure & 13.25 & 1.18 & - \\
\hline
\end{tabular}

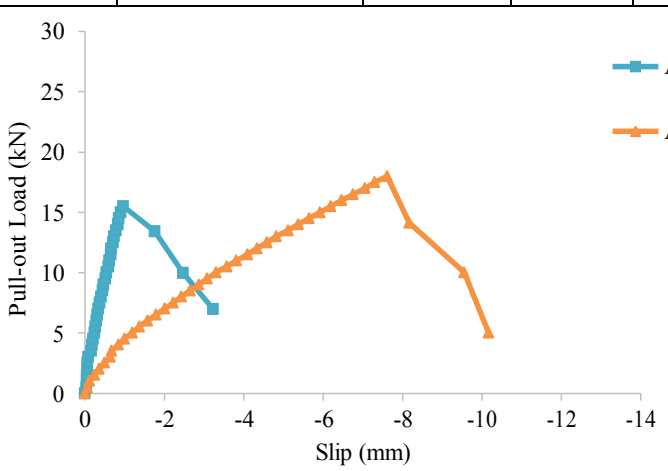

Fig. 9e. The pull-out load and slip curve of specimens with knit bamboo type 1 coated with varnish

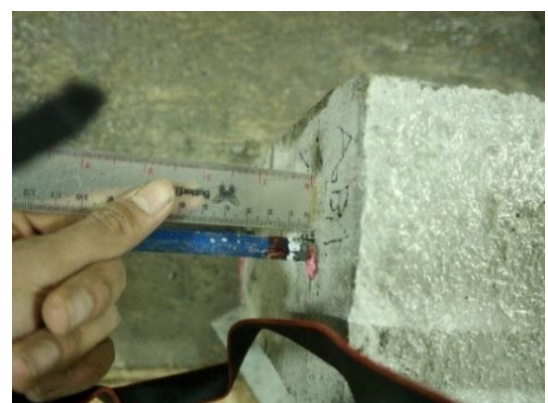

Fig. 10. Pull-out failure pattern of specimen reinforced with plain bamboo

It is shown with shear failure on the contact surface between concrete and reinforcement. According to the American Concrete Institute standard code, there are three types of collapse in the pull-out test, including tensile failure, concrete collapse followed by pulling out of the reinforcement, and collapse by pulling out of reinforcement in concrete.

The bond stress can be analyzed in the case of plain bamboo bars that embedded in concrete went through the pull-out failure, as seen in Fig.10.

On the other hand, the pull-out test of specimens reinforced with the knit bamboo result in tensile failure, that is taken into account the tensile stress of bamboo, as seen in Fig. 11. The roughness between knit bamboo and concrete improve because of interlocking between bars' void and concrete. The bonding between knitted bamboo and concrete is also influenced by the improvement of concrete quality.

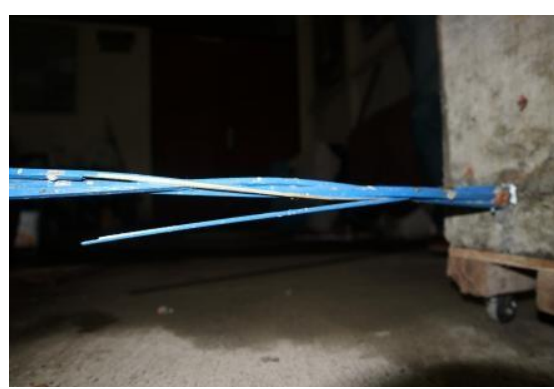

(b)

Fig. 11. Tensile failure pattern of specimens reinforced with knit bamboo

\subsection{Bond stress analysis based on pull-out test}

Table 5. Bond stress analysis of specimens.

The pull-out results took into account either the bond stress or the tensile stress, depending on the tensile failure. The obtained tensile stress, $\mu_{\mathrm{T}}$ in the pull-out test is the ratio between the pull-out load and cross-section area of bamboo.

As seen in Table 5, it is prior known that knit bamboo embedded in concrete can go through tensile failure in the pull-out test. The bond between bamboo and concrete increases so that the tensile failure of reinforcement occurs.

On the other hand, the plain bamboo has less bonding with concrete, so that bond failure or pull-out failure occurs here. Then, bond stress can be obtained.

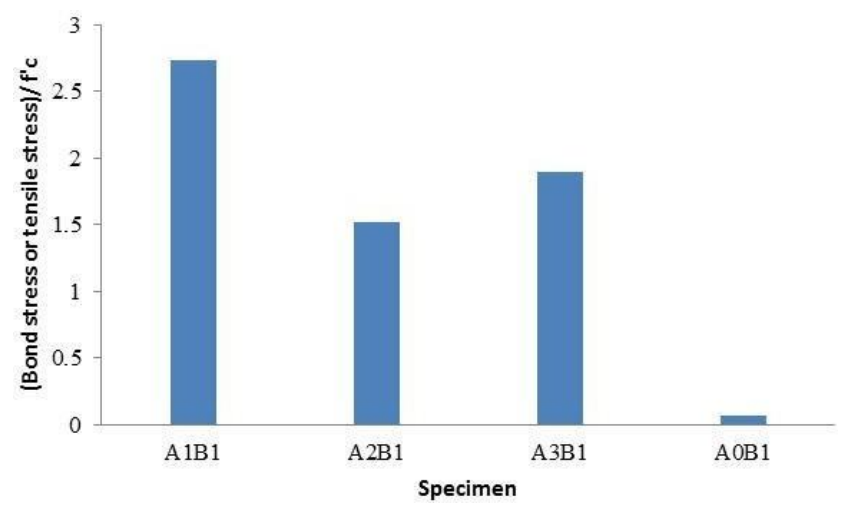

Fig. 12. The ratio between either the bond stress or the tensile stress and concrete compressive strength

Figure 12 shows the ratio between either the bond stress or the tensile stress and concrete compressive strength in the pull-out specimens. Knit bamboo embedded in the pull-out specimens more increased the ratio than plain bamboo one. It means that knit bamboo has good friction with concrete, which prevents the bond failure. 


\section{Conclusions}

Based on the result and discussion of the research, it can be concluded as follows:

a. Knit bamboo effects on the pull-out load improvement, because it contributes to the friction force between reinforcement and concrete. It can result in tensile failure in the pull-out test, that means it has great friction or bonding with concrete. So, it is found that the bond stress is influenced by the friction force between bamboo and concrete

b. Sikadur as a bonding agent can be recommended as good coating compared with varnish because it can increase the bond stress as well as the pull-out load.

c. Plain bamboo result pull-out failure. It means there is no good bonding between plain bamboo and concrete.

This research was supported by the Ministry of Research, Technology and Higher Education. All authors would like to express my special thanks to Technical Support Staff and College Students who helped in doing this research.

\section{References}

1. A. Atul, N. Bharadwaj, M. Damodar, EICTBRCBC, 71, 610-617 (2014)

2. A. Rochman, PKTBBBBCPKL, 16, 1-9 (2005)

3. G. Winter, A.H. Nilson, Design of concrete structures (McGraw-Hill Inc., Boston, 1994)

4. R. L Park, T. Paulay, Reinforced concrete structures (Wiley, 1975)

5. E. G. Nawy, Reinforced concrete: $A$ Fundamental Approach (Prentice Hall, 2009)

6. J. C. McCormac, Design of reinforced concrete (John Wiley \& Sons, 2003).

7. D. Nuralinah, S.M. Dewi, R.M. Simatupang, A. Pujiraharjo, ANPOTMBRVTDP, RCCE-ICCER 2017. (under review by IJASEIT scientific committee) 